Article

\title{
Consumer Preferences for Local Food: Testing an Extended Norm Taxonomy
}

\author{
Julius Wenzig ${ }^{1}$ and Tim Gruchmann ${ }^{2, *(1)}$ \\ 1 Centre for Sustainable Corporate Leadership, Witten/Herdecke University, Alfred-Herrhausen-Str. 50, \\ 58448 Witten, Germany; julius.wenzig@uni-wh.de \\ 2 Supply Chain Management, Kassel University, Kleine Rosenstr. 1-3, 34109 Kassel, Germany \\ * Correspondence: tim.gruchmann@gmail.com
}

Received: 5 April 2018; Accepted: 20 April 2018; Published: 24 April 2018

\begin{abstract}
Consumer attitudes toward consuming and buying locally produced food are well studied. By contrast, the topic of consumer preferences for local food, with a special emphasis on the role of norms, still lacks empirical evidence. To study the influence of norms and morals on the intention to buy local food products, a quantitative study $(\mathrm{N}=327)$ focusing on external social and internalized moral norms was conducted using the constructs of the theory of planned behavior in combination with an extended norm taxonomy and the perceived consumer effectiveness measure. The norm constructs consisted of two different personal norms, integrated and introjected, and two social norms, descriptive and injunctive. In a factor analysis, two factors for social norms but only one for personal norms were obtained. Multiple regressions explained 50 percent of the variance in intentions and 29 percent of the variance in past behavior. Norm constructs were proven important in the model, as personal norms had the largest effect among all constructs on intentions, and descriptive norms strongly influenced past behavior. An additional mediation analysis showed that personal norms were internalized social injunctive norms and that intentions mediated the relationship between all constructs. The implications of the findings and recommendations for future research are given accordingly.
\end{abstract}

Keywords: local food; theory of planned behavior; personal and social norms; consumer preferences

\section{Introduction}

Local food is a growing trend for various reasons. The globalization of food supply chains and the will to support the local economy, as well as several food scandals, can account for the increasing number of concerned consumers who prefer to obtain their food from a local source $[1,2]$. Additionally, local food products are associated with freshness, higher quality, and healthiness [3]. As a consequence, more sustainable and alternative food networks such as the Slow Food movement (a movement to support traditional and regional cuisine, which encourages farming in local ecosystems), community-supported agriculture (CSA; a network to connect producers and consumers of food more closely to share risks and food), and farmers' markets (where farmers sell directly to consumers) have become increasingly popular in many Western countries $[4,5]$.

One way that scientific research, including the present study, can contribute to a more sustainable food supply chain is to provide insights into consumer attitudes and preferences. Consumer attitudes toward consuming and buying locally produced food are fairly well researched [4]. However, the topic of consumer preferences for local food, with a special emphasis on the role of norms, still lacks empirical evidence, e.g., for different product categories [6]. Many studies have provided evidence that morals and norms account for variations in environmentally responsible consumer behavior. Along this line, internalized personal or moral norms can contribute significantly to our understanding 
of human behavior [7]. Similarly, social norms have received growing attention from researchers trying to explain impulses in favor of collective outcomes [8,9]. Norm research can form the basis for policies to protect the environment, help marketers and decision makers in the industry to understand their customers, and support campaigners from non-governmental organizations (NGOs) in persuading the society of their goals [10]. Hence, the present study intends to contribute to the understanding of consumer preferences for local food by extending the scope of the investigation to norms and empirically investigating their importance.

To study norms and morals regarding local food, a quantitative study focusing on external social norms and more internalized moral norms was conducted. Social norms are based on social expectations and constitute a standard construct in the theory of planned behavior (TPB) [11]. A small number of studies have focused on personal norms in different pro-environmental behaviors. For example, studies have focused on choosing eco-friendly mobility alternatives [12], buying electric vehicles [13], recycling [14,15], and buying fresh and processed organic food [16]. Just recently, Kumar and Smith [17] examine the antecedents and consequences of consumer attitudes toward local food taking a TPB theoretical lens. Therefore, the TPB is a solid theory with which to study the influence of norms and to build upon. By doing so, this quantitative study yielded robust results, which can be tested for their significance and relevance in relation to some of the basic measures provided in the TPB.

The structure of the study is as follows: Section 2 provides an overview of the most important scientific contributions concerning consumer preferences for local food. Section 3 presents the theoretical lens of the TPB [18] and the extended norm taxonomy by Thøgersen [19]. Section 4 discusses the sampling strategy of this quantitative study and the measures used. Section 5 presents the results of the exploratory factor analysis, regression analysis, and mediation analysis. It examines the role of felt obligation, guilt appeals, the implications of expectations, and the actions of significant others in the domain of local food. Section 6 discusses the implications of the empirical study, while Section 7 identifies the study limitations and future research directions.

\section{Literature Review}

There is no standard definition for local food [20]. Therefore, it is difficult to differentiate local food from non-local food. Generally, different players in the food market have different perceptions of what is understood as local food. Local food is described in the literature according to a variety of criteria. Distinctions can be made based on geographic or perceived areas, cultural criteria, natural history, and municipal boundaries or distances, but these distinctions are not mutually exclusive.

The concept of food miles constitutes the focus of many studies $[3,20,21]$, where consumers associate local food with distances from 10 to 200 miles. In other studies, the distance is measured in hours of driving [22] or state wise [23]. Some consumers stated that for food to be called local, it must come from locally owned farms [23]. In their review on local food, Feldmann and Hamm [4] found no relationship between the country of origin and the accepted traveling distance. However, studies from the United States [23] and Germany [24] showed that consumers consider food that comes from their federal state as local.

\subsection{Sociodemographics}

Most of the studies on consumer perceptions and preferences for local food measured the influence of demographic characteristics to explain the results or make them more tangible for marketers. Even if demographics were never the focus of these studies, they could contribute to explaining why consumers buy local food. Zepeda and Deal [25] argued that demographic characteristics could serve as a proxy for the change in preferences induced by rising incomes. However, reviewed studies that developed economic and/or demographic profiles of local food shoppers produced different results $[26,27]$. These suggest that demographics tend to be weak proxies for preferences. Along these 
lines, Bond et al. [28] pointed out that demographics could be weak proxies due to the recent growth numbers in local food from all sociodemographic groups.

While Zepeda and Li [29] did not find any relationship between demographics and attitudes toward local food, many other studies have revealed that females who are older and wealthier tend to buy local food more often than other consumers $[3,27,28,30]$. Older people tend to be more settled and connected with their area and therefore develop a tendency to buy local food. By contrast, younger people tend to be more cosmopolitan and do not mind buying food from non-local sources. However, no clear turning point in age could be found. Some studies have shown that people from urban areas tend to buy more local food $[27,30]$, while other studies have found that rural consumers tend to buy more local food [3,31].

To find out more about consumer perceptions of local food, Zepeda and Nie [32] used an alternative methodological approach. Based on a quantitative questionnaire, they clustered consumers using so-called food-related lifestyles. This resulted in four different consumer lifestyle groups that all act differently when it comes to consuming local food. Thus, what is measured is not the individual probability of consuming local food but the probability of pertaining to a certain group. Zepeda and Nie [32] found that being part of a minority had a much stronger impact on being in a particular lifestyle group than family composition, age, or gender. However, they claimed that an overrepresentation of minorities in organic and local food consumption occurs in many studies, which could be explained by a stronger food culture and a greater interest in food attributes and cooking [32].

\subsection{Context}

A possible reason why many studies have had different results when looking at demographic variables is that the context of the participants is different. Context refers to all external influences on food purchases, such as policies, regulations, costs, availability, and personal relationships [25]. The context can be negative and impede behavior, or it can be positive and foster behavior. Context was first introduced by Guagnano et al. [14] as a moderator for the effect of attitude (and potentially behavior). This would mean, for instance, that if consumers are generally fond of local food, it is publicly available, and its prices are not too high, then consumers will most probably end up purchasing local food. On the other hand, if prices are very high, those same consumers might reconsider and choose non-local food. Nonetheless, attitudes can outperform limiting contextual factors when they are very strong. For instance, if a person holds very strong positive attitudes toward local food, then he/she might overcome limiting barriers such as less convenience or less variety due to seasonal limitations. Similarly, even a solid positive attitude toward local food can be outperformed if the exogenous factors are strong. The most frequent types of contextual factors mentioned are availability, convenience, price, and seasonal variety [25].

Regarding context constructs, the attitude-behavior gap measured in many studies can be explained accordingly. For example, results from a focus group discussion showed that although consumers shared a high interest in local food, the amount of local food bought daily was low [33]. In a similar vein, focus group participants of a study by Zepeda and Leviten-Reid [22] were enthusiastic about the concept of local food production but admitted that a lack of availability in their local grocery store could easily prevent them from buying local food products.

\subsection{Attitudes}

Attitudes and motivations regarding consuming food of local provenance differ greatly among studies but mostly involve nutrition, freshness, freedom from chemicals, concerns about the environment, and support of farmers and the local economy [32]. Following Born and Purcell [34], the benefits of local food can be characterized along three main dimensions: (1) social and economic justice; (2) food quality and health; and (3) ecological sustainability.

The relevance of social and economic justice to local food has been supported in several studies. The support of local business was shown to be a strong motivation, often combined with the possibility 
to socially interact with local farmers to maintain relationships [21,26,27,31,35,36]. Concern for equity in the food chain was shown to be high even among consumers who rarely attend food markets or buy local food [22]. Similarly, membership in a CSA is associated with being socially and politically aware [36]. Focusing on the concern for food supply chain issues, Tregear and Ness [26] found that consumers were particularly concerned about overseas competition and the vulnerability of small firms and local shops.

Studies have suggested that the practical benefits of food, such as freshness, taste, healthiness, appearance, and availability, have a far greater impact on consumer choices and food preferences than factors of social and economic justice [37]. For instance, Conner et al. [30] found that the factor with the highest mean importance for consumers when shopping at farmers' markets was food quality and safety from food-borne illnesses. The second most important factor for consumers was the ability to support local farms. However, practical factors do not always seem to influence local food purchasing behavior. Bond et al. [28] found that local food shoppers place less emphasis on location as well as physical and aesthetic appeal than non-local food shoppers. Those consumers also express a relatively stronger preference for fresh and unprocessed food.

In addition, consumers associate local food with ecological sustainability due to more sustainable production methods, fewer food miles, and, in turn, less greenhouse gas emissions. Therefore, researchers have argued that those involved in sustainable food consumption also tend to consume local products. A construct closely related to sustainable consumption is the perceived consumer effectiveness (PCE). PCE is the degree to which an individual feels that he/she can make a difference in policy, society, and/or the ecological environment. Roberts [38] showed that PCE can explain about a third of the variation in civic consumer behavior. With respect to ecological sustainability, Zepeda and Nie [32] found that having high environmental concern (i.e., caring for the environment) was mediated with a being an adventurous consumer, and thus influences buying local food positively.

\subsection{Research Gaps}

According to the literature review by Feldmann and Hamm [4], further research is needed to study the role of social and personal norms in predicting local food purchasing behavior. Thus, one can argue that while recent studies have investigated the importance of values and beliefs, norms were not included or were only marginally included. Answering this demand, Lorenz et al. [6] provided a first study to examine the effects of subjective and personal norms on the intention to purchase local food in the context of regional pork. As the importance of norms has not been investigated in a more general context so far, it is worth empirically replicating this study in a broader context. Accordingly, the present study intends to contribute to the literature by strengthening the empirical evidence of norms in this vein.

\section{Theoretical Lens}

The TPB proposed by Ajzen $[18,39]$ is a theoretical lens with which to investigate behavior and its drivers in social psychology. This theoretical framework has been used in a large variety of settings and behavioral phenomena (for a meta-analytic overview, see [11]). According to Ajzen's [18] model, a certain behavior is determined by the intention to perform this behavior, which in turn is influenced by perceived behavioral control ( $\mathrm{PBC}$ ), the attitude toward that behavior, and social norms. An antecedent of the TPB is the theory of reasoned action (TRA) [40,41], which suggests that behavior depends solely on attitude and social norms. Attitude refers to the degree to which a person has a favorable or unfavorable evaluation of a certain behavior [18] (see Section 2.3). However, contextual factors such as limited availability often influence the intention to perform a certain behavior. That is why Ajzen $[18,39]$ incorporated PBC into the model; many researchers consider the TPB to be the more comprehensive behavioral theory with more explanatory power in comparison with TRA [42]. The related framework extended by PCE is presented in Figure 1. Here, the relationship between intention and behavior is straightforward. The stronger the intention to perform a certain behavior, 
the more likely its performance should be. However, the relationship between intention and behavior is built on the assumption that human beings attempt to make rational decisions based on the information available to them [42]. Therefore, behavior that is not consciously performed cannot be explained by the TPB [43].

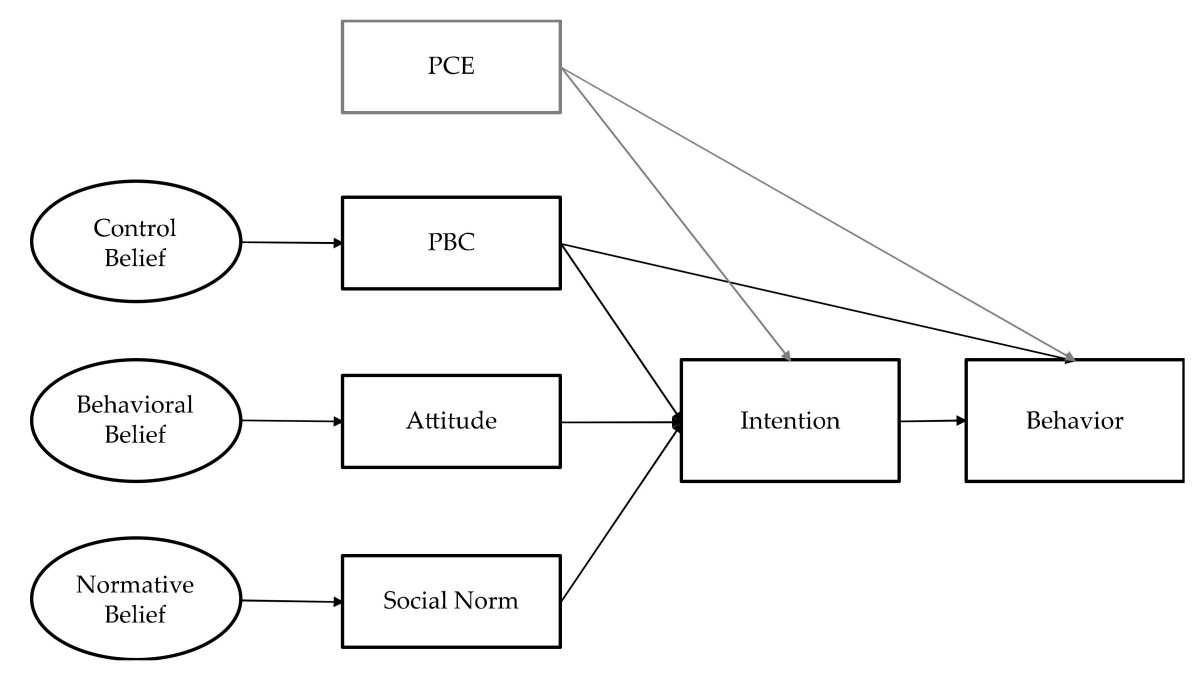

Figure 1. Theoretical framework of the theory of planned behavior.

\subsection{Perceived Behavioral Control}

PBC describes the subjective degree of control over the performance of the behavior [44]. It indicates whether someone perceives that he/she can perform a certain behavior with ease or only with (much) difficulty, and it is assumed to reflect past experiences as well as anticipated conditions. Hence, PBC can hamper intention, and thus behavior, when someone is insecure about whether he/she can perform the behavior [45]. PBC reflects both inner control factors as well as external perceived difficulty factors and barriers [46]. Related to sustainable products such as local food, both perceived product availability [47] as an external perceived barrier and PCE [38] as an inner control factor have been found to be significantly related to PBC. Perceived product availability relates to a consumer's feeling about whether a product can be easily obtained or consumed. Even though a certain consumer has high motivation to buy a product, it is possible that this intention is hampered by the low real or perceived availability of the good [1]. PCE is especially relevant in situations with normative reasoning [38]. Regarding sustainable products such as local food, a high PCE, indicating that consumers feel they can contribute positively to problems regarding the conventional food chain, is often an indicator that consumers buy such products [45].

The TPB has often been applied in the area of food choice with significant results $[1,16,42,43,45,48]$. However, only a limited number of studies have applied the TPB in the field of local food consumption $[6,20,45,49]$. Onozaka et al. [20] found that consumers who primarily buy their local food from direct channels, such as farmers' markets or directly from farms, exhibited a stronger influence from significant others and a higher perceived product availability when compared to others. Similarly, consumers who primarily buy their food from direct markets had a higher PCE than those who shop primarily at supermarkets. Nurse Rainbolt et al. [49] found that an extended model of TPB, including PCE, was only significant for locally grown apples but not for tomatoes. Here, PCE was shown to significantly increase the predictions for buying local food. Vermeir and Verbeke [45] also used the TPB to predict local food purchasing behavior and showed in a stepwise multiple regression that attitude, social norms, PCE, and perceived availability could explain 50 percent of the variance in intentions. To find answers to the research gap as to how personal and social norms influence local food buying behavior, the influence of norms shall be investigated in the following part. 


\subsection{Extended Norm Taxonomy}

Norms, in general, are considered shared beliefs about how we should act. Norms are usually enforced by the threat of sanctions or the promise of rewards [50]. Norms can be internal or external. Internal norms are often called personal or moral norms [50]. External norms are often called social, subjective, or perceived [40]. A social norm refers to the perceived social pressure to perform or not perform a certain behavior [45]. Norms are called social when they are based on group expectations and the sanctions and rewards are externally defined and imposed. Therefore, individuals adhere to social norms because of social pressure, be it real or imagined. Personal norms, on the other hand, are defined as self-expectation experienced as a moral obligation [50]. Personal norms are different from social norms because "expectations, sanctions, and obligations that are tied to personal norms are anchored in the self, whereas those tied to social norms are anchored in a social group" [51] (p. 2508).

Along this line, Schwartz [50] developed the norm activation model (NAM) to explain altruistic behavior. Personal norms are the core of the model and are mainly driven by two factors: "the awareness that performing (or not performing) the particular behavior has certain consequences, and the feeling of responsibility for performing the specific behavior" [52] (p. 142). Furthermore, personal norms are described as actively experienced feelings of moral obligation, which directly influence behavior. This is different from the TPB, where norms, attitudes, and PBC are considered to influence intentions, which in turn influence behavior. To understand the effect of norms on local food buying behavior, the TPB shall be extended with the core notion of the NAM, the personal norm. The traditional TPB model [18] includes only social norms but including personal norms in the model is one of the most common extensions [53]. A meta-analysis of the effect of personal norms in the framework of the TPB showed that it increases the explained variance in intentions by an average of 3 percent while controlling for all the TPB variables [53]. In certain cases, including personal norms can substantially increase the explained variance.

Intention used to be perceived as very similar to personal norms. However, in the NAM, Schwartz [50] showed that norms need to be activated in certain situations for them to influence behavior or intention. A norm is activated when "(a) someone is aware of the consequences of one's behavior for the welfare of others, and (b) one ascribes at least some responsibility for these consequences to oneself" [51] (p. 2507). When these conditions are met, personal norms are activated, and a feeling of personal obligation starts guiding behavior. Thus, feelings of personal obligation can be neutralized and therefore do not necessarily lead to the formation of intentions. This is how the notions of intention and personal norm differ. In an environmental setting, being confronted with the climate crisis but denying its seriousness or not feeling responsible for it can stop the activation process of the norm. By contrast, someone with the intention to save the environment has passed this point and will be more likely to behave pro-environmentally. A review of the inclusion of moral norms in the TPB model found that norms were particularly strongly activated in behavior with substantial consequences for the welfare of others [53]. Hence, applying different norm constructs to local food consumption seems to be promising in the context of local food. According to Schwartz [50], personal norms are also different from attitudes because they each evaluate a distinct dimension. Whereas personal norms focus solely on evaluations of acts in terms of their moral worth for the self, attitudes can refer to a broader variety of concepts based on material, social, or psychological components [51].

The roots of personal norms are internal reasons, which are consistent with internalized values and norms including conceptions of right and wrong or good and bad. Similar to social norms, personal norms come with expectations that they will be fulfilled. The difference is that these are self-administered and expressed negatively via the feeling of guilt, self-depreciation, and loss of self-esteem or expressed positively via pride, security, enhanced self-esteem, and other positive self-evaluations [10]. Norms are often employed to explain behavior such as helping, cooperation, or pro-environmental behavior. Pro-environmental behavior is usually correlated with both social and personal norms [15]. Interestingly, when the influence of social and personal norms on pro-environmental behavior is empirically tested, social norms do not show a strong influence and 
personal norms account for much more of the explained variance. However, whether internalized personal norms or external social norms are responsible for a certain behavior is often unclear [54,55].

To better distinguish between social and personal norms, Thøgersen [19] tried to focus on the motivational content of norms. He argued that in the studies referred to by Schwartz [50], pro-social behavior is positively correlated with anticipated guilt or pride and less strongly correlated with personal obligation (i.e., personal norms). However, when personal obligation is entered into a regression analysis with anticipated guilt, anticipated guilt or pride is no longer significant. This is consistent with the notion that anticipated guilt or pride influences behavior, which is mediated by felt obligation. Nevertheless, the anticipation of guilt is only part of the motivational content of personal norms.

Regarding the relationship between anticipated guilt and felt obligation, Thøgersen [19] argued that it is in accordance with the NAM not to set these two constructs as equal but to see them as variable, depending on the particular person and situation. He argued that the anticipation of guilt is distinct from personal norms and can be seen as a subtype of internalized norms. According to Deci and Ryan [54] as well as Ryan and Deci [55], behavior is only regulated by anticipated guilt or pride when norms are not fully accepted. Then, social pressure is replaced by an inner pressure perceived as anticipated guilt from one's inner voice. Therefore, anticipated guilt mainly plays a role in shaping moral norms when social norms are superficially internalized without much reflection on how they match personal values and goals. For instance, when an individual gets a guilty conscience when buying food from a continent far away, he/she would much rather buy local food compared with other consumers. These semi-internalized personal norms enforced by anticipated pride or guilt are called introjected norms [19].

The other part of the motivational basis for moral norms, according to Thøgersen [19], consists of reflections on how the norm and its outcomes relate to one's own values and beliefs. According to Kohlberg [56], these reflections and elaborate processing might lead to deeper internalization than introjected norms. Hence, these kinds of norms differ from introjected norms in terms of motivational content and internalization. Therefore, Thøgersen [19] introduced integrated norms as a subtype of personal norms, which reflect inner beliefs and reflections. For instance, an individual who feels a deep personal obligation to buy local food will be much more committed than an individual who is indifferent to local food.

As with personal norms, Thøgersen [19] employed a finer distinction for social norms. This is partly because many studies have reported a weak relationship between the social norm construct and intentions. One reason for this weakness may be the narrowness of the construct [57]. Researchers have argued that social norms and normative influences may have finer nuances and may vary in several ways. In the context of local food, Kumar and Smith [17] found that subjective norms are positively related to the intention of buying local food products. One common approach to specifying the social norm construct is to distinguish between descriptive and injunctive norms [8]. This is based on the crucial distinction between the "ought" (injunctive) and the "is" (descriptive) meaning of social norms. The injunctive meaning of social norms refers to rules or beliefs that ought to be done and that seem morally approved or disapproved. Closely connected is the notion of social sanctions, which could occur if a certain behavior is not followed. The injunctive norm is close to the concept of the social norm in the TRA and the TPB [18]. However, often enough, what is morally approved (injunctive) is what is normally done (descriptive). Nevertheless, the concept and motivation are different, and it is worthwhile to understand the normative influence and separate them [8]. The proposed norm taxonomy by Thøgersen [19] is summarized in Figure 2.

Thøgersen [19] established some evidence that the four norm constructs have discriminative validity and a significant influence on different pro-environmental behaviors. Doran and Larsen [12] were able to distinguish descriptive, injunctive, and personal norms in a factor analysis but did not include introjected norms in their study. Klöckner et al. [13] were only able to distinguish two factors 
for all four norm constructs. Accordingly, the present study deploys the full norm taxonomy proposed by Thøgersen [19] in the context of local food products.

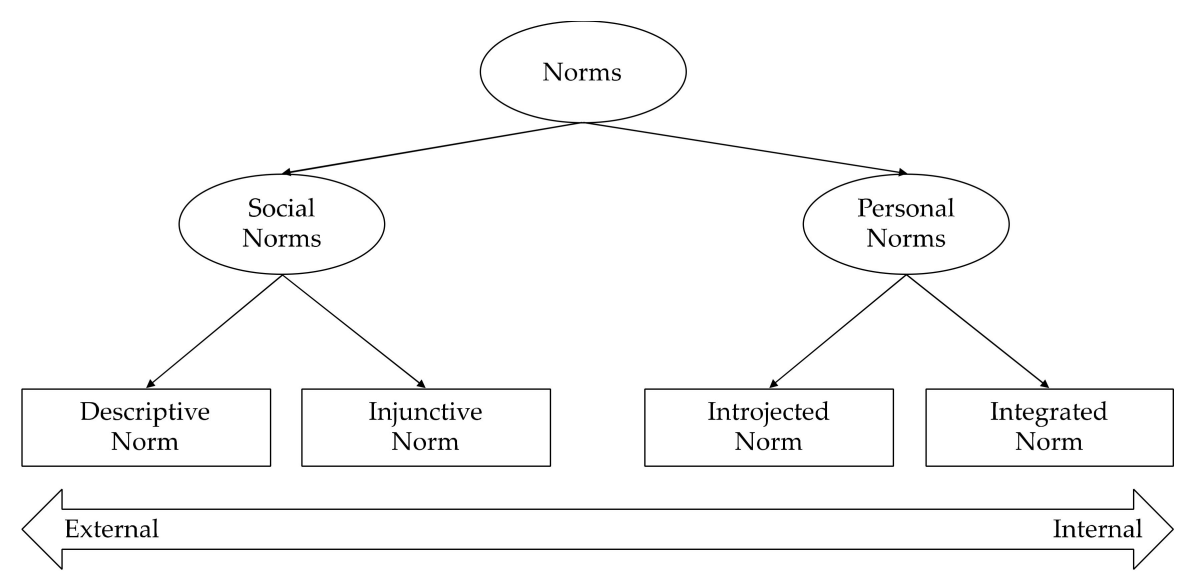

Figure 2. Extended norm taxonomy [58].

\section{Methodology}

\subsection{Data Collection}

Survey data were collected through a self-administered questionnaire based on an extended theoretical framework, which included the full norm taxonomy as proposed by Thøgersen [19]. The hypothesized framework is presented in Figure 3. The related constructs of the questionnaire are displayed in Table 1. Table 1 also shows the measures used in the study together with the descriptive data (mean value and standard deviation) and a code for each item.

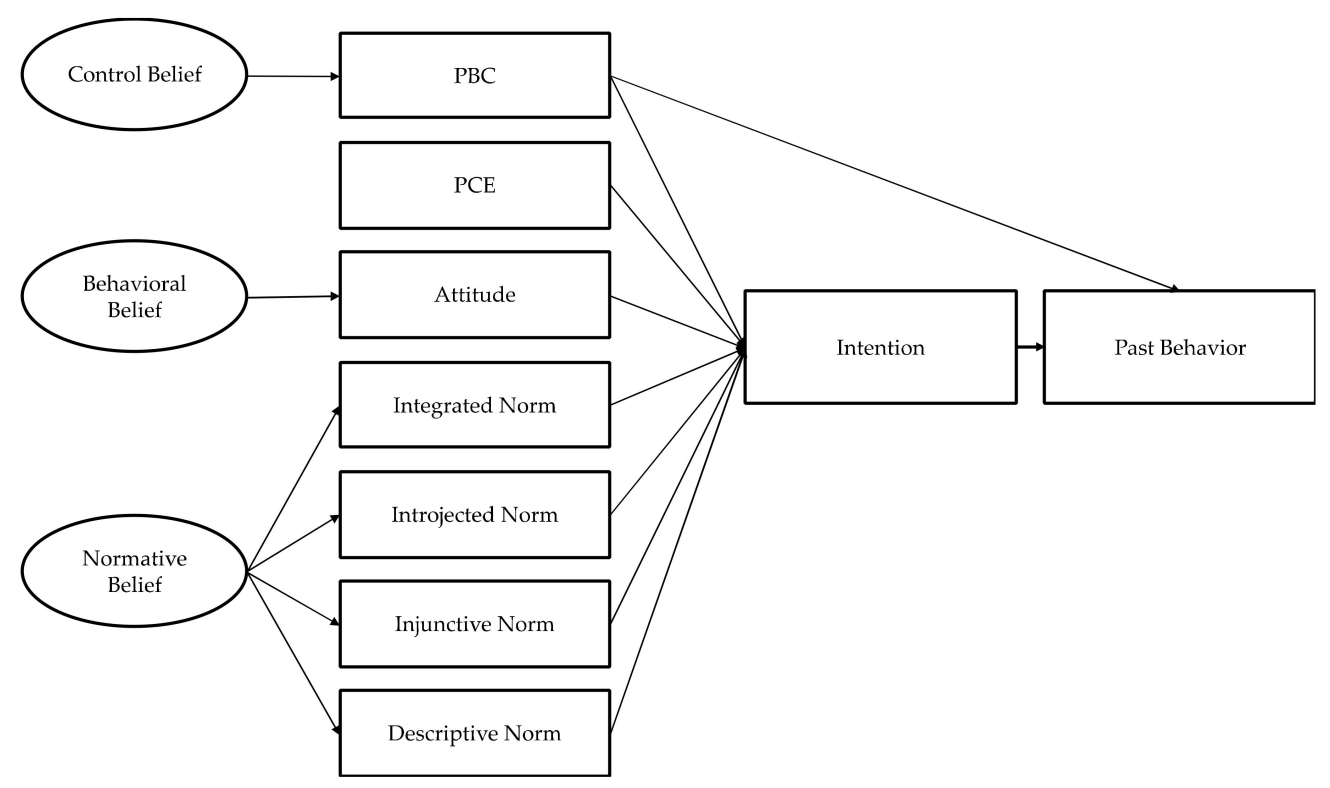

Figure 3. Theoretical framework of the study $[4,44,56]$.

The participants $(\mathrm{N}=327)$ for this survey were recruited via email and social media. Nearly a fifth of the participants (about 60) were students and scientific employees of the Witten/Herdecke University. The remaining participants were recruited mostly via social media. Most of these participants (about 270) were also students or graduates. There were no financial incentives and questions concerning 
research aims or the content of the study. The questionnaire took about $4.5 \mathrm{~min}$ on average to answer. The goals and the approximate duration of the study were given together with an assurance that all data would be collected anonymously.

Table 1. Constructs and items.

\begin{tabular}{|c|c|c|c|c|}
\hline Constructs & Items & Code & Mean & SD \\
\hline Past Behavior & How often have you bought local food in the last three months? ${ }^{a}$ & $\mathrm{BH} 1$ & 5.12 & 1.514 \\
\hline \multirow{3}{*}{ Intention } & I intend to buy local food in the next three months. ${ }^{b}$ & IN 1 & 5.19 & 1.576 \\
\hline & I will make an effort to buy local food in the next three months. ${ }^{b}$ & IN 2 & 5.31 & 1.557 \\
\hline & I will try to buy local food in the next three months. ${ }^{b}$ & IN 3 & 5.35 & 1.516 \\
\hline \multirow{6}{*}{ Attitude } & Overall, I think that buying local food is enjoyable/ unenjoyable. ${ }^{c}$ & AT 1 & 6.16 & 1.045 \\
\hline & Overall, I think that buying local food is good/bad. ${ }^{c}$ & AT 2 & 6.34 & 0.936 \\
\hline & Overall, I think that buying local food is harmful/beneficial. ${ }^{c}$ & АТ 3 & 6.21 & 1.233 \\
\hline & Overall, I think that buying local food is foolish/wise. ${ }^{c}$ & AT 4 & 6.32 & 1.110 \\
\hline & Overall, I think that buying local food is pleasant/unpleasant. ${ }^{c}$ & AT 5 & 5.28 & 1.414 \\
\hline & Overall, I think that buying local food is favorable/unfavorable. ${ }^{c}$ & AT 6 & 5.61 & 1.349 \\
\hline \multirow{3}{*}{$\begin{array}{l}\text { Perceived } \\
\text { Behavioral Control }\end{array}$} & For me, buying local food is "extremely easy" to "extremely difficult". ${ }^{d}$ & PBC 1 & 4.32 & 1.623 \\
\hline & If I want to, I can easily buy my food locally. $\mathrm{e}$ & PBC 2 & 4.43 & 1.696 \\
\hline & How likely is it that, if you try, you will be able to buy your food locally? ${ }^{e}$ & $\mathrm{PBC} 3$ & 5.31 & 1.461 \\
\hline \multirow{4}{*}{$\begin{array}{l}\text { Perceived } \\
\text { Consumer } \\
\text { Effectiveness }\end{array}$} & It is worthless for individual consumers to do anything about pollution. ${ }^{b}$ & PCE 1 & 1.74 & 1.339 \\
\hline & $\begin{array}{l}\text { When I buy products, I try to consider how my use of them will affect the } \\
\text { environment and other consumers. }{ }^{b}\end{array}$ & PCE 2 & 4.85 & 1.566 \\
\hline & $\begin{array}{l}\text { Since one person cannot have any effect on pollution and natural resource } \\
\text { problems, it doesn't make any difference what I do. }{ }^{b}\end{array}$ & PCE 3 & 1.65 & 1.113 \\
\hline & $\begin{array}{l}\text { Each consumer's behavior can have a positive effect on society by } \\
\text { purchasing products sold by socially responsible companies. }{ }^{b}\end{array}$ & PCE 4 & 6.12 & 1.299 \\
\hline \multirow{3}{*}{ Personal Norm } & My own values make me feel obligated to buy local food. ${ }^{b}$ & PN 1 & 5.50 & 1.482 \\
\hline & Buying local food is deeply rooted in my value system. ${ }^{b}$ & PN 2 & 4.63 & 1.870 \\
\hline & I feel obliged to buy local food. ${ }^{b}$ & PN 3 & 4.47 & 1.874 \\
\hline \multirow{3}{*}{ Introjected Norm } & When I buy food from other continents instead of local food, I feel bad. ${ }^{b}$ & INT 1 & 3.88 & 1.827 \\
\hline & I get a guilty conscience when I do not buy local food. ${ }^{\mathrm{b}}$ & INT 2 & 3.80 & 1.705 \\
\hline & When I buy food from far away, I get a guilty conscience. ${ }^{\mathrm{b}}$ & INT 3 & 3.84 & 1.852 \\
\hline \multirow{5}{*}{ Social Norm } & My family thinks I should buy local food. ${ }^{b}$ & SC 1 & 4.40 & 1.866 \\
\hline & My friends expect me to buy local food. ${ }^{b}$ & SC 2 & 3.36 & 1.695 \\
\hline & $\begin{array}{l}\text { People, who influence my buying behavior, think I ought to buy local } \\
\text { food. }\end{array}$ & SC 3 & 4.01 & 1.728 \\
\hline & Many people in the society think I should buy local food. ${ }^{b}$ & SC 4 & 4.00 & 1.571 \\
\hline & People who are important to me expect me to buy local food. ${ }^{b}$ & SC 5 & 3.74 & 1.806 \\
\hline \multirow{5}{*}{ Descriptive Norm } & I believe that many people, who are important to me, buy local food. ${ }^{b}$ & DN 1 & 4.31 & 1.392 \\
\hline & I think the members of my family buy local food. $b$ & DN 2 & 4.40 & 1.590 \\
\hline & In my perspective, many of my friends buy local food. $b$ & DN 3 & 3.99 & 1.401 \\
\hline & In my view, people, who influence my buying behavior, buy local food. ${ }^{b}$ & $\mathrm{DN} 4$ & 4.13 & 1.511 \\
\hline & I believe that many people in the society buy local food. ${ }^{\mathrm{b}}$ & DN 5 & 3.53 & 1.538 \\
\hline
\end{tabular}

a Measured on a 7-point scale with the values -3: "never" and +3: "frequently"; b Measured on a 7-point scale

with the values -3 : "strongly disagree" and +3 : "strongly agree"; " ${ }^{c}$ Measured on a 7-point scale from -3 to +3 ;

$\mathrm{d}$ Measured on a 7-point scale with the values -3 : "extremely easy" and +3 : "extremely difficult"; ${ }^{\mathrm{e}}$ Measured on a

7-point scale with the values -3: "extremely likely" and +3: "extremely unlikely".

Young adults were included in the study because they are the consumers of the future. They are the ones who will shape the food system in the next decades, especially as they will have considerable spending power. Since they come from a higher educational background, they should have some knowledge of the food system and concepts of sustainability. Without some prior awareness of sustainability, responses on issues such as product availability, PCE, and attitudes and norms toward buying local food would be highly speculative and hypothetical. However, there are also inherent dangers in including the younger generation in the study. According to the NAM [50], norms (especially personal norms) are only activated when individuals possess an awareness of the consequences of their actions for others and when they accept personal responsibility for those actions. There is some evidence that adolescents and young adults, as compared to older adults, are less likely 
to feel aware of the consequences of their actions and accept less responsibility for the consequences of their negative actions [53]. A meta-analytic review on the inclusion of moral norms in the TPB model found that age is a moderating factor of normative behavior. The overall relationship between morals and intention was stronger among older as compared to younger samples [53]. Therefore, norms might not turn out to have a significant influence on local food buying behavior among the chosen sample.

\subsection{Procedures and Measures}

All constructs of the questionnaire were measured on a 7-point Likert scale with values from -3 to +3 ("never" to frequently", "strongly disagree" to "strongly agree", "extremely likely" to "extremely unlikely"). These scales were chosen because Preston and Colman [58] pointed out that 7-point Likert scales show higher indices of reliability, validity, and discriminating power than Likert scales with below 5 points. The scales were all taken from other publications and altered for use in the context of local food. The scales were originally in English and translated into German for the questionnaire. To test the scales, the Cronbach's alpha measure of reliability was employed. In a meta-analysis on the Cronbach's alpha coefficient, Peterson [59] provided evidence that a value below 0.60 is unacceptable, 0.70 is low, $0.80-0.90$ is moderate to high, and 0.90 is high. First, the participants were given a text about the background and content of the study. Second, the respondents were asked about their past local food buying behavior using an adapted one-item scale [60]. The influence of injunctive norms was measured using an adapted scale by Vermeir and Verbeke [45], which showed a moderate to high Cronbach's alpha of 0.86 for the five items. However, in the original study, injunctive norms were labeled "social norms" which is consistent with Thøgersen's [10] claim that injunctive norms are most similar to the "social norm" construct in the TPB. Third, the influence of personal norms was measured using an adapted three-item scale from Klöckner et al. [13]. The overall reliability of that scale was high $(\alpha=0.89)$. Fourth, the measure for introjected norms was taken from Klöckner et al. [13] and adapted for this study; it exhibited high reliability $(\alpha=0.94)$. Then, PBC was measured using an adapted three-item scale from Sparks et al. [61], which likewise had a high Cronbach's alpha of 0.89 . Results showed that if the third measure of PBC was deleted, then the overall Cronbach's alpha would increase by 0.003 . Since this value is very small, the item was retained in the measure.

In the next step, the participants were exclusively asked about their attitudes toward buying local food, using a scale from Povey et al. [57]. The Cronbach's alpha for the six items was 0.87, which is highly reliable. In the last step, the impact of descriptive norms was measured using a scale from Vermeir and Verbeke [45]. The reliability of the scale was low at first $(\alpha=0.79)$. However, the last item of the scale (DN 5) suggesting that many people in the society buy local food showed very low overall correlations with the other items. Field [62] recommended excluding variables that have several correlations below 0.30 . Therefore, this item was excluded from the analysis. After deleting item DN 5, the Cronbach's alpha for the whole scale increased by 0.068 to an overall reliability of 0.86 . Moreover, the PCE measure by Roberts [38] was used without modifications. This measure showed low reliability $(\alpha=0.71)$, which was similar to the reliability of the PCE scale $(\alpha=0.72)$ in the original study by Roberts [38]. Finally, the intention to buy local food in the next three months was tested using a scale from Sparks et al. [61]. The Cronbach's alpha for the scale was very high $(\alpha=0.95)$.

\section{Data Analysis}

\subsection{Exploratory Factor Analysis}

To test the theoretical framework on norms, an exploratory factor analysis was performed. All items of the different norm constructs were entered into a principal component analysis (PCA) with orthogonal rotation (varimax).

The Kaiser-Meyer-Olkin (KMO) measure verified the sample size adequacy for the analysis $(\mathrm{KMO}=0.895)$. All KMO values for the individual items were above .84 , which is well above the accepted value of 0.50. According to Field [62], this is a "great" value for the overall KMO and well 
above the given limit of 0.50 for the individual items. The Bartlett's test of sphericity, $\chi^{2}(105)=3645.92$, $p<0.001$, showed that correlations between items were sufficiently large for PCA.

An initial analysis showed that only two components had eigenvalues over Kaiser's criterion of 1; they explained 63.64 percent of the variance. However, the scree plot in Figure 4 showed inflections that would justify retaining three components. Given the scree plot and an eigenvalue of 0.958 for the third component, close to the border of 1 , three factors were retained, explaining 70.03 percent of the variance. The results of the factor loadings after rotation are reported in Table 2. Following the PCA, only three factors could be retained, resulting in a combined factor for integrated and introjected norms, which will be called personal or moral norms. For each descriptive and injunctive norm, one factor was retained. Therefore, the norm taxonomy elaborated by Thøgersen [19] was only partly confirmed by the PCA.

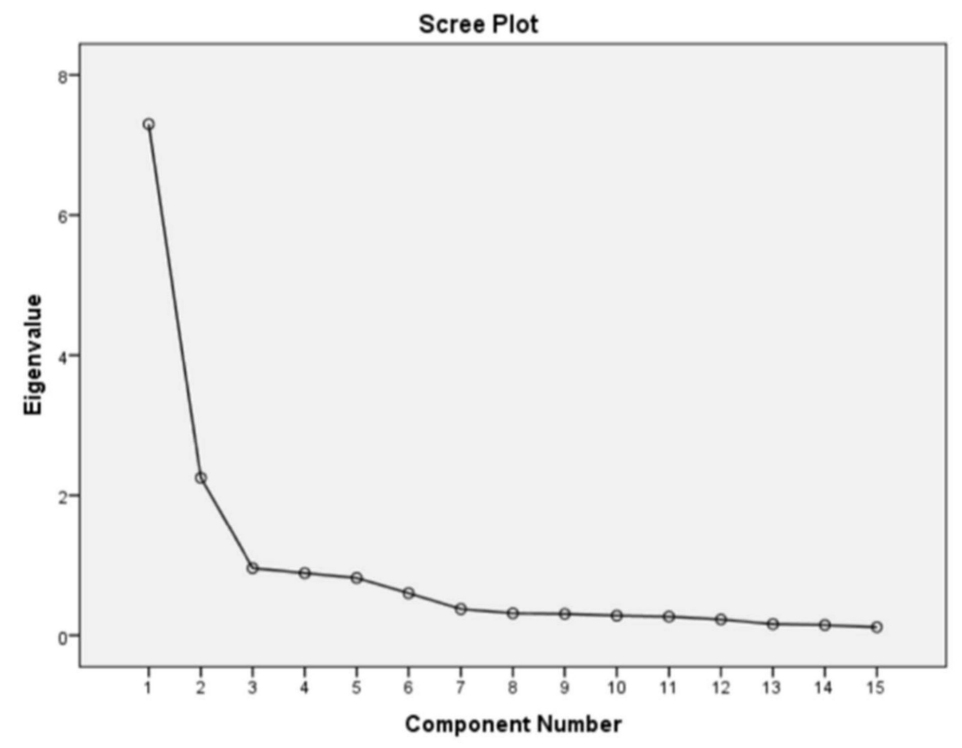

Figure 4. Scree plot for norm constructs.

Table 2. Rotated component matrix.

\begin{tabular}{cccc}
\hline \multicolumn{4}{c}{ Rotated Component Matrix } \\
\hline Item & Factor 1 & Factor 2 & Factor 3 \\
\hline PN 1 & $\mathbf{0 . 6 7 2}$ & 0.430 & 0.156 \\
PN 2 & $\mathbf{0 . 6 5 9}$ & 0.454 & 0.118 \\
PN 3 & $\mathbf{0 . 6 5 3}$ & 0.470 & 0.203 \\
INT 1 & $\mathbf{0 . 9 0 9}$ & 0.046 & 0.171 \\
INT 2 & $\mathbf{0 . 8 9 2}$ & 0.068 & 0.164 \\
INT 3 & $\mathbf{0 . 8 8 9}$ & 0.082 & 0.131 \\
SC 1 & 0.066 & $\mathbf{0 . 8 0 2}$ & 0.239 \\
SC 2 & 0.203 & $\mathbf{0 . 7 7 8}$ & 0.321 \\
SC 3 & 0.211 & $\mathbf{0 . 7 2 0}$ & 0.412 \\
SC 4 & 0.183 & $\mathbf{0 . 6 2 4}$ & 0.247 \\
SC 5 & 0.189 & $\mathbf{0 . 5 2 5}$ & 0.418 \\
DN 1 & 0.098 & 0.250 & $\mathbf{0 . 8 2 6}$ \\
DN 2 & 0.199 & 0.207 & $\mathbf{0 . 7 6 8}$ \\
DN 3 & 0.242 & 0.394 & $\mathbf{0 . 7 4 0}$ \\
DN 4 & 0.141 & 0.361 & $\mathbf{0 . 7 1 1}$ \\
\hline Eigenvalues & 4.012 & 3.447 & 3.045 \\
Percent of variance & 26.747 & 22.983 & 20.300 \\
$\boldsymbol{\alpha}$ & 0.914 & 0.862 & 0.861 \\
\hline
\end{tabular}

Note: Factor loadings over 0.500 appear in bold. 


\subsection{Regression Analysis}

A hierarchical multiple regression analysis was performed to analyze the relationships proposed by the TPB and the norm constructs. As recommended by DiStefano et al. [63], all constructs were computed from the single items using factor scores (Anderson-Rubin) to obtain standardized and more exact scores. Factor scores also have the advantage of giving more weight to a given item if the loading value is high. Table 3 shows the intercorrelations among the measured constructs. Very weak to strong correlations were evident between each of the variables. All constructs were positively correlated and at least weakly significant. Moral norms $(r=0.589, p<0.001)$, PCE $(r=0.533 . p<0.001)$, and attitudes $(r=0.514, p<0.001)$ were the most strongly correlated with intentions. Past behavior and intentions were significantly $(p<0.001)$ and moderately $(r=0.492)$ correlated. PBC was the most weakly associated with intentions $(r=0.234, p<0.001)$. PBC in general had moderate correlation coefficients with the other constructs $(r<0.267)$. As hypothesized by Thøgersen [10], moral norms were more strongly correlated with injunctive norms $(r=0.513, p>0.001)$ than with descriptive norms $(r=0.462, p<0.001)$, representing the overall norm taxonomy where the norm constructs differ according to their internalization. This underlying structure was also true for descriptive norms, which were more strongly correlated with injunctive norms $(r=0.694, p<0.001)$ than with moral norms $(r=0.462, p<0.001)$. Past behavior showed lower correlations with the other constructs than intentions did. The other constructs showed no conspicuousness.

Table 3. Correlation coefficients for the measured constructs.

\begin{tabular}{|c|c|c|c|c|c|c|c|}
\hline & 1. & 2. & 3. & 4. & 5. & 6. & 7. \\
\hline 1. Intention & - & & & & & & \\
\hline 2. $\mathrm{PBC}$ & $0.234 * * *$ & - & & & & & \\
\hline 3. Attitude & $0.514^{* * *}$ & $0.222 * * *$ & - & & & & \\
\hline 4. Social Norm & $0.375^{* * *}$ & $0.167^{* *}$ & $0.260^{* * *}$ & - & & & \\
\hline 5. Moral Norm & $0.589 * * *$ & $0.163^{* *}$ & $0.392 * * *$ & $0.513^{* * *}$ & - & & \\
\hline 6. Descriptive Norm & $0.412 * * *$ & $0.266^{* * *}$ & $0.316^{* * *}$ & $0.694^{* * *}$ & $0.462^{* * *}$ & - & \\
\hline 7. PCE & $0.533^{* * *}$ & $0.116^{*}$ & $0.421^{* * *}$ & $0.302^{* * *}$ & $0.506^{* * *}$ & $0.329^{* * *}$ & - \\
\hline 8. Past Behavior & $0.492 * * *$ & $0.240^{* * *}$ & $0.247^{* * *}$ & $0.325^{* * *}$ & $0.397^{* * *}$ & $0.391^{* * *}$ & $0.374^{* * *}$ \\
\hline
\end{tabular}

In the stepwise regression analysis on intentions, two outliers were eliminated from the sample (respondents \#303 and \#144); they showed Mahalanobis distances of 21 and 52, respectively. Given the sample of 327 respondents, this was estimated to cause concern for the overall reliability of the data [62]. There were also three datasets that showed a very low covariance ratio outside the calculated parameters [62], which would have improved the overall explained variance by about 4 percent in each step of the regression analysis. However, due to solid values for Cook's distance and Mahalanobis distance in these datasets, they were retained in the analysis. In this regression, the TPB variables were entered first, followed by the remaining norm constructs and, finally, the measures of PCE and past behavior. The results of the regression analysis on intentions are shown in Table 4 . The TPB predictor variables of attitudes, injunctive norms, and PBC were entered first (Table 4) and explained 33.9 percent of the variance in intentions. Attitudes and injunctive norms had significant beta weights in the regression equation ( $\beta=0.430, p<0.001$ and $\beta=0.257, p<0.001$, respectively). PBC was not significant and had a much smaller effect $(\beta=0.083, p=0.076)$. Moral and descriptive norms were added at step 2 . The $\mathrm{R}^{2}$ change was 12.5 , leading to a total of 46.5 percent of the explained variance. However, injunctive norms and PBC were not significant. At this step, moral norms $(\beta=0.413, p<0.001)$ had the highest beta value, followed by attitudes $(\beta=0.318, p<0.001)$. The beta weight for descriptive norms was considerably lower $(\beta=0.119)$ and only weakly significant $(p>0.05)$. In the last step, PCE was entered in the regression analysis (step 3, Table 5). An extra 3.5 percent of $R^{2}$ change was achieved, leading to a total of 50 percent of the explained variance. Moral norms and attitudes still 
had the highest beta values ( $\beta=0.326, p<0.001$ and $\beta=0.258, p<0.001$, respectively). Injunctive norms, PBC, and descriptive norms were all non-significant. PCE had a beta weight of $0.228(p>0.001)$. Multicollinearity did not seem to be a problem, as the average variance inflation factor (VIF) was 1.659. The Durbin-Watson test (2.161) showed that the assumption of independent errors was tenable.

Table 4. Hierarchical multiple regression analysis to predict intention $(\mathrm{N}=325)$.

\begin{tabular}{|c|c|c|c|c|c|c|}
\hline Step & Variables & $\mathbf{R}^{2}$ & $\mathbf{R}^{2}$ Change & B & SE B & $\beta$ \\
\hline \multirow[t]{4}{*}{1} & & 0.339 & $0.339^{* * *}$ & & & \\
\hline & Attitude & & & 0.451 & 0.050 & $0.430^{* * *}$ \\
\hline & Injunctive Norm & & & 0.257 & 0.047 & $0.258^{* * *}$ \\
\hline & PBC & & & 0.084 & 0.047 & 0.083 \\
\hline \multirow[t]{6}{*}{2} & & 0.465 & $0.125^{* * *}$ & & & \\
\hline & Attitude & & & 0.318 & 0.048 & $0.303^{* * *}$ \\
\hline & Injunctive Norm & & & -0.002 & 0.060 & -0.002 \\
\hline & PBC & & & 0.060 & 0.043 & 0.060 \\
\hline & Moral Norm & & & 0.413 & 0.051 & $0.412^{* * *}$ \\
\hline & Descriptive Norm & & & 0.119 & 0.060 & 0.119 * \\
\hline \multirow[t]{7}{*}{3} & & 0.500 & $0.035^{* * *}$ & & & \\
\hline & Attitude & & & 0.258 & 0.048 & $0.245^{* * *}$ \\
\hline & Injunctive Norm & & & 0.002 & 0.058 & 0.002 \\
\hline & PBC & & & 0.066 & 0.042 & 0.065 \\
\hline & Moral Norm & & & 0.326 & 0.053 & $0.325^{* * *}$ \\
\hline & Descriptive Norm & & & 0.043 & 0.057 & 0.043 \\
\hline & PCE & & & 0.228 & 0.048 & $0.228^{* * *}$ \\
\hline
\end{tabular}

Note: ${ }^{*} p<0.05 ; * * * p<0.001$.

Table 5. Hierarchical multiple regression analysis to predict past behavior $(\mathrm{N}=327)$.

\begin{tabular}{|c|c|c|c|c|c|c|}
\hline Step & Variables & $\mathbf{R}^{2}$ & $\mathbf{R}^{2}$ Change & B & SE B & $\beta$ \\
\hline \multirow[t]{2}{*}{1} & & 0.225 & $0.225^{* * *}$ & & & \\
\hline & Intention & & & 0.718 & 0.074 & $0.474^{* * *}$ \\
\hline \multirow[t]{5}{*}{2} & & 0.265 & $0.040 * *$ & & & \\
\hline & Intention & & & 0.623 & 0.087 & $0.412 * * *$ \\
\hline & Attitude & & & -0.072 & 0.084 & -0.047 \\
\hline & Injunctive Norm & & & 0.221 & 0.079 & $0.146^{* *}$ \\
\hline & PBC & & & 0.215 & 0.075 & $0.142^{* *}$ \\
\hline \multirow[t]{7}{*}{3} & & 0.283 & 0.019 * & & & \\
\hline & Intention & & & 0.520 & 0.097 & $0.343^{* * *}$ \\
\hline & Attitude & & & -0.092 & 0.083 & -0.061 \\
\hline & Injunctive Norm & & & 0.022 & 0.105 & 0.015 \\
\hline & PBC & & & 0.193 & 0.075 & 0.127 * \\
\hline & Moral Norm & & & 0.152 & 0.097 & 0.100 \\
\hline & Descriptive Norm & & & 0.243 & 0.105 & 0.160 * \\
\hline \multirow[t]{8}{*}{4} & & 0.294 & $0.010 *$ & & & \\
\hline & Intention & & & 0.462 & 0.100 & $0.305^{* * *}$ \\
\hline & Attitude & & & -0.122 & 0.084 & -0.080 \\
\hline & Injunctive Norm & & & 0.026 & 0.104 & 0.017 \\
\hline & PBC & & & 0.202 & 0.075 & $0.133^{* *}$ \\
\hline & Moral Norm & & & 0.100 & 0.100 & 0.066 \\
\hline & Descriptive Norm & & & 0.230 & 0.104 & 0.152 ** \\
\hline & PCE & & & 0.194 & 0.090 & 0.128 * \\
\hline
\end{tabular}


A hierarchical regression analysis was also conducted with past behavior as the dependent variable. No outliers were removed because of solid values for Cook's distance and Mahalanobis distance in these datasets (see Table 5). In the first step, intentions were entered in the regression analysis, which explained 22.5 percent of the variance in past behavior $(\beta=0.474, p<0.001)$. In the second step, the traditional measures of the TPB were entered in the regression model. The explained variance in past behavior amounted to 26.5 percent, but the $\mathrm{R}^{2}$ change was less significant than before $(p<0.01)$. Intentions still had the highest influence, but injunctive norms $(\beta=0.146, p<0.01)$ and PBC also had considerable beta weights $(\beta=0.142, p<0.01)$. Attitudes, however, had negative non-significant beta weights ( $\beta=-0.061, p=0.393$ ). In the last step, PCE was added in the regression analysis, and a total of 29.4 percent of the variance was explained. PCE had moderate significance weights $(\beta=0.128, p<0.01)$. The significance levels of descriptive norms and PBC were higher than before, while the other constructs remained roughly the same. Again, looking at the average VIF, multicollinearity was not a problem (1.758). The Durbin-Watson test showed no sign of auto-correlation (1.926).

\subsection{Mediation Analysis}

Thøgersen [19] suggested that personal norms are often a product of the internalization of social norms. To test this hypothesis, a mediation analysis using a bootstrap method was conducted [64]. The bootstrapping method provides several advantages [65] over the popular method of Baron and Kenny [66]. As recommended in the literature, a total of 5000 bootstrap samples and $95 \%$ bias-corrected and accelerated confidence intervals $(\mathrm{BCa} \mathrm{CI})$ were used. In this method, the significance is indicated by the $95 \%$ confidence interval not crossing zero. However, the significance is not always the most important measure in mediation analysis since it only proves that mediation has not happened by chance. The decreasing effect, displayed as the B value, of the independent variable on the dependent variable when the mediator is entered in the model is often a much stronger indicator of mediation [65]. When it comes to reporting effect size, there is ambiguity in the scientific literature. Wen and Fan [67] stated that the traditional measure of the mediation effect size, $\mathrm{P}_{\mathrm{M}}$ (the ratio of the indirect effect to the total effect), together with some other statistical information, should be given for basic mediation models. However, Hayes and Rockwood [65] advised against this as it has no upper and lower bound; instead, they recommended the partially standardized indirect effect (defined as the indirect effect divided by the standard deviation of the independent variable). Miočević et al. [68] recommended more advanced measures based on Bayesian estimators but stated that the most commonly used measure of effect size is still the $\mathrm{P}_{\mathrm{M}}$ ratio of the indirect effect to the total effect. As $\mathrm{P}_{\mathrm{M}}$ seems to be the standard choice for reporting the effect size and it is easy to interpret, this measure was also used in the present study.

First, the influence of injunctive norms on intentions through personal norms was tested. The independent variable of injunctive social norms, the dependent variable of behavioral intentions, and the mediating variable of personal norms were entered in the model. Figure 5 summarizes the significant indirect effect of injunctive social norms on intentions through personal norms $(B=0.25$, $95 \% \mathrm{BCa}$ CI [ 0.25 to 0.45$])$. This is underlined by the finding that the effect of injunctive norms is a significant predictor of intentions $(B=0.41, p<0.001)$ but becomes non-significant when personal norms $(\mathrm{B}=0.54, p<0.001)$ are added to the model $(\mathrm{B}=0.06, p=0.275)$. Additionally, the unstandardized $\mathrm{B}$ values decrease substantially to almost zero, which can be compared because all items were measured on a 7-point scale. The $\mathrm{P}_{\mathrm{M}}$ ratio is 0.61 . Often, in the social sciences, when talking about mediation analysis, studies analyze whether there is partial or full mediation. However, Hayes [64] (pp. 170-172) argued that complete and partial mediation concepts have little value and should be abandoned. 


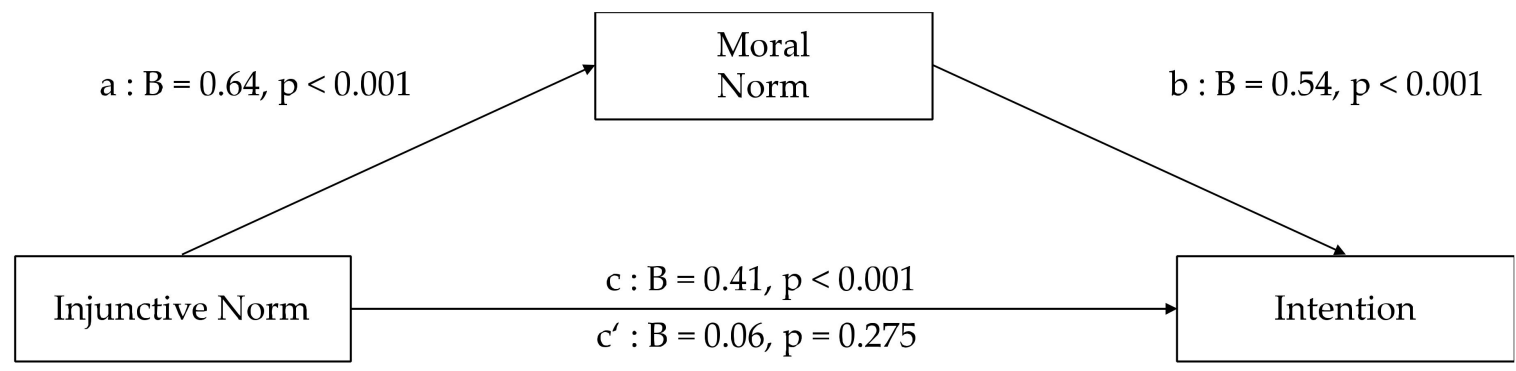

Indirect effect, $\mathrm{B}=0.25 ; 95 \% \mathrm{BCa} \mathrm{CI}[0.25$ to 0.45$]$

Figure 5. Mediation of injunctive norms on intentions through moral norms.

As descriptive norms are also considered social norms, their effect on intention through personal norms was tested. The results are displayed in Figure 6. The effect of descriptive norms on intentions is significantly mediated by moral norms ( $\mathrm{B}=0.34,95 \% \mathrm{BCa} C \mathrm{CI}[0.25$ to 0.45$])$. The $\mathrm{P}_{\mathrm{M}}$ ratio of the mediating effect of moral norms in the relationship between descriptive norms and intentions is 0.67 .

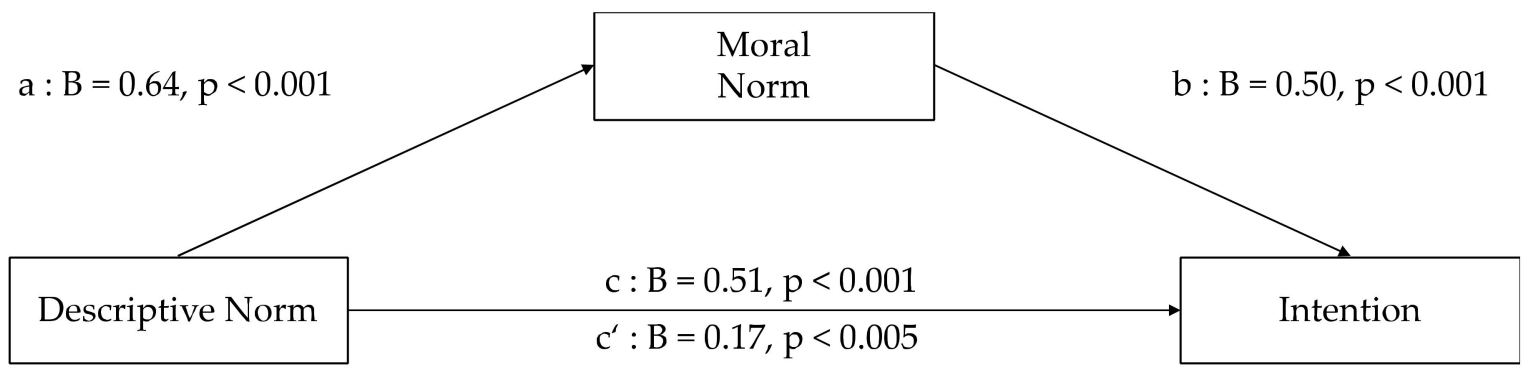

Indirect effect, $\mathrm{B}=0.34 ; 95 \% \mathrm{BCa}$ CI $[0.25$ to 0.45$]$

Figure 6. Mediation of descriptive norms on intentions through moral norms.

However, in contrast to injunctive norms, the effect of descriptive norms on intentions remained significant when controlling for moral norms $(B=0.17, p<0.005)$. This means that a considerable share of descriptive norms is not mediated but has its own influence on intentions and past behavior.

Because a considerable share of descriptive norms was not mediated through moral norms, this study tested whether social norms might be the mediator between descriptive norms and both intentions and past behavior, as suggested by Thøgersen's [19] norm taxonomy (norms differ according to their internalization). Figure 7 displays the results of this mediation analysis. Interestingly, the mediating effect of injunctive norms between descriptive norms and intentions was significant but rather weak $\left(\mathrm{P}_{\mathrm{M}}\right.$ ratio $\left.=0.29\right)$. This shows that descriptive norms are much less or not mediated through injunctive or moral norms.

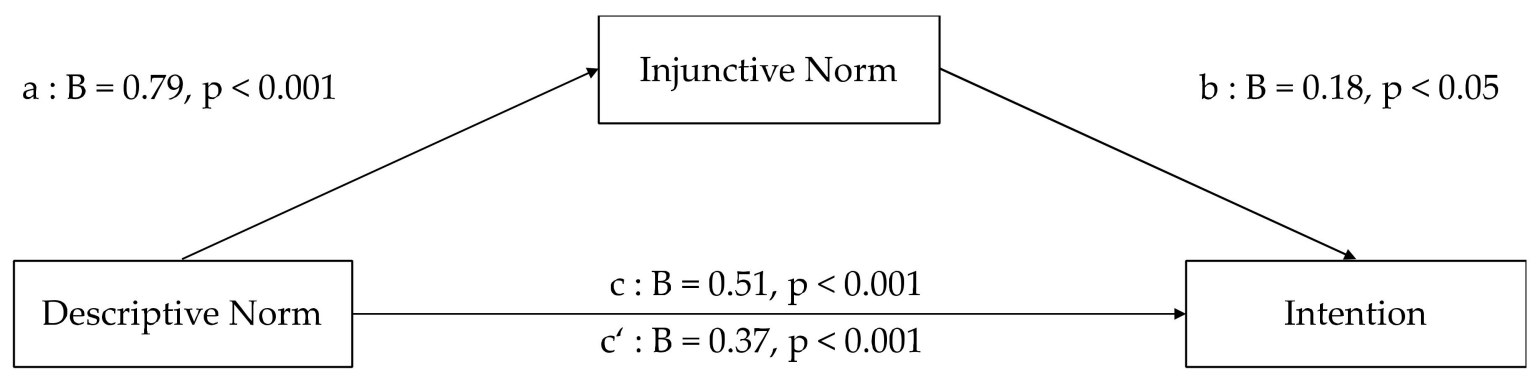

Indirect effect, $\mathrm{B}=0.15 ; 95 \% \mathrm{BCa} \mathrm{CI}[0.03$ to 0.26$]$

Figure 7. Mediation of descriptive norms on intentions through injunctive norms. 
Table 6 displays the results of the analysis on the mediating effect of intentions between past behavior and the constructs used in the study. All constructs were significantly mediated by intentions. However, some constructs seemed to be more strongly mediated than others. Attitudes, for instance, seemed to be the most strongly mediated, as the B value became negative and non-significant when intentions were added. The $\mathrm{P}_{\mathrm{M}}$ ratio was 1.02. Similarly, the B values for moral norms and PCE were more than halved when the mediating role of intentions was added to the model ( $\mathrm{P}_{\mathrm{M}}$ ratio of 0.58 and 0.54 , respectively). Injunctive and descriptive norms as well as $\mathrm{PBC}$ were only moderately mediated by intentions.

Table 6. Mediation of the effect of constructs on past behavior through intentions.

\begin{tabular}{|c|c|c|c|c|}
\hline Constructs & $\begin{array}{c}\text { Effect of } \\
\text { Constructs on Past } \\
\text { Behavior (c) }\end{array}$ & $\begin{array}{l}\quad \text { Effect of } \\
\text { Constructs on Past } \\
\text { Behavior Together } \\
\text { with Intention }\left(c^{\prime}\right)\end{array}$ & $\begin{array}{c}\text { Indirect Effect of } \\
\text { Constructs on Past } \\
\text { Behavior with } 95 \% \\
\text { BCa CI }\end{array}$ & $\begin{array}{l}\text { PM Ratio the } \\
\text { Indirect Effect to } \\
\text { the Total Effect }\end{array}$ \\
\hline Attitude & $\mathrm{B}=0.35^{* * *}$ & $B=-0.00$ & $\mathrm{~B}=0.36 ;[0.21$ to 0.54$]$ & $\mathrm{P}_{\mathrm{M}}=1.02$ \\
\hline Injunctive Norm & $\mathrm{B}=0.34^{* *}$ & $\mathrm{~B}=0.17^{* *}$ & $\mathrm{~B}=0.17 ;[0.11$ to 0.26$]$ & $\mathrm{P}_{\mathrm{M}}=0.50$ \\
\hline PBC & $\mathrm{B}=0.25^{* * *}$ & $\mathrm{~B}=0.15^{* *}$ & $\mathrm{~B}=0.09 ;[0.04$ to 0.17$]$ & $P_{M}=0.36$ \\
\hline Moral Norm & $\mathrm{B}=0.39 * * *$ & $\mathrm{~B}=0.16^{* *}$ & $\mathrm{~B}=0.23 ;[0.14$ to 0.34$]$ & $\mathrm{P}_{\mathrm{M}}=0.58$ \\
\hline Descriptive Norm & $\mathrm{B}=0.46^{* * *}$ & $\mathrm{~B}=0.26^{* *}$ & $\mathrm{~B}=0.19 ;[0.12$ to 0.30$]$ & $\mathrm{P}_{\mathrm{M}}=0.41$ \\
\hline PCE & $\mathrm{B}=0.59^{* * *}$ & $\mathrm{~B}=0.26^{* *}$ & $\mathrm{~B}=0.32 ;[0.21$ to 0.46$]$ & $\mathrm{P}_{\mathrm{M}}=0.54$ \\
\hline
\end{tabular}

\section{Discussion and Conclusions}

The present study aimed at extending the scope of the investigation to the importance of norms in local food buying behavior. Therefore, an overview of the most relevant contributions on consumer preferences for local food was provided. To examine the role of social and personal norms, an empirical quantitative study was conducted.

The ТРB [18], one of the dominant theories in social psychology, and an extended norm taxonomy [19], including various social and personal norms, were chosen as the theoretical framework. The combination of these two theories is reasonable because social norms are a standard construct of the TPB and including personal norms is one of the most common extensions of the theory [53]. However, Thøgersen [19] classified social norms further into descriptive (i.e., what people normally do) and injunctive norms (i.e., what is expected from others). Personal norms were categorized into introjected (i.e., having a guilty conscience when [not] performing a certain action) and integrated norms (i.e., feeling a moral obligation). Additionally, PCE was added based on Roberts [38].

The theoretical norm framework was only partly supported by the exploratory factor analysis. Descriptive and injunctive social norms could be distinguished, but for introjected and integrated norms, only one factor (i.e., personal or moral norms) was extracted. This finding is partly in line with that of Klöckner et al. [13], who extracted only two factors-one for social norms and one for personal norms. Doran and Larsen [12], who did not distinguish between introjected and integrated norms, were also able to extract three factors.

The findings from the correlation analysis showed that all four norm constructs in addition to the TPB constructs and PCE were positively related to behavioral intentions and past behavior. The participants were more likely to intend to buy and actually buy local food when they also believed that others act in a similar way (i.e., descriptive norms), when others important to them expect them to (i.e., injunctive social norms), and when they have a guilty conscience or feel a moral obligation to do so (i.e., personal norms). These findings are also consistent with those of Doran and Larsen [12] as well as Klöckner et al. [13].

To gain further insights, a stepwise regression analysis with the dependent variable of intentions was conducted. Results showed that attitudes, PBC, and injunctive norms explained 33 percent of 
the variance in intentions. However, PBC was not significant. When personal and descriptive norms were added in the second step, injunctive norms also turned out to be not significant. Moral norms, followed by attitudes, had the largest influence on intentions. Together, the variables explained 45 percent of the variance. The finding that social norms are not significant when analyzed together with personal norms is consistent with that of many other studies $[15,54,55]$. When PCE was added in the third step, the total explained variance rose by 3.5 percent to a total of 50 percent. The exact same amount of explained variance was obtained by another study that analyzed local dairy products in Belgium with the TPB measures combined with perceived availability [45]. Similarly, a meta-review on pro-environmental behavior found that similar variables explained an average of 52 percent of the variance in intentions [69].

To test the relationships between the norm constructs, a mediation analysis was conducted. It showed that injunctive norms were strongly mediated by moral norms. They were non-significant and had weak influence when entered together with moral norms in a regression analysis. This means that, in this sample, personal moral norms are internalized injunctive norms. Injunctive norms only affect intentions with personal norms as the mediator. This finding is in line with mediation analyses in other studies $[10,12]$. In another mediation analysis, the effect of descriptive norms was significantly mediated by personal norms but much less strongly than injunctive norms. This means that even though consumers have a strong personal moral obligation to buy local food, the actions of significant others are still relevant to their purchasing behavior, while social expectations play a minor role. In an experimental setting, Smith et al. [70] examined the relationship between descriptive and injunctive norms. They found that these constructs need to be aligned (i.e., people buying local food and expecting it of others) to affect intentions the most.

To test the basic notion of the TPB, a stepwise regression to predict past behavior was also conducted. Intentions were entered first and proved highly significant, with a strong positive effect resulting in 22.5 percent of the explained variance. When the traditional measures of the TPB were entered in the regression, only injunctive norms and $\mathrm{PBC}$ turned out to be significant and positive. Attitudes did not play a role in predicting past behavior while controlling for intentions. This finding is consistent with that of Jackson et al. [71], who found that attitudes have a significant positive effect on intentions but not on behavior when controlling for intentions. When moral and descriptive norms were entered, only the latter had a significant positive effect on past behavior. By contrast, Harland et al. [51] found that moral norms had a positive effect on past behavior, although they did not control for intentions in the regression analysis. In the last step in the current study, PCE was added and had a significant positive contribution to predicting behavior. The total amount of explained variance reached 29.4 percent, including intentions, the TPB measures, the remaining norm constructs, and PCE. In sum, intentions explained 22.5 percent of the variance while all other constructs explained only an additional 7.1 percent. In a meta-review on pro-environmental behavior, an average coefficient of determination for behavior of 27 percent was found using the TPB measures, social (i.e., injunctive) and moral norms, feelings of guilt (i.e., introjected norms), problem awareness, and internal attribution [69]. Thus, the results of this thesis are in line with other findings.

In another analysis, the mediating effect of intentions in the relationship between the other constructs and past behavior was measured. The study showed that all constructs were mediated significantly by intentions, but a substantially decreased effect size was proven only for several constructs. Attitudes were strongly mediated by intentions. Additionally, moral norms and, less so, PCE were mediated by intentions. This result explains why attitudes have one of the greatest effects on intentions but are entirely non-significant and negative when entered together with intentions as independent variables in a regression analysis on past behavior. The same holds, to a lesser extent, for moral norms and PCE, which seem to be strongly mediated by intentions. The mediating effect of intentions on the relationship between moral norms and behavior is also consistent with a meta-review that found that moral norms are important predictors of intentions but do not seem to directly predict behavior [53]. 
Descriptive norms did not prove to be strongly mediated by moral norms. According to Thøgersen's [19] norm theory, it is also possible that descriptive norms are mediated by injunctive norms (which is the next step in the internalization process). However, descriptive norms, at their core, are different from injunctive norms because they are, by definition, distinct concepts. Injunctive norms are mediated by moral norms, which in turn are mediated by intentions. Descriptive norms have a considerable share in explaining past behavior directly (but not in explaining intentions) and are only weakly mediated by moral norms. The reasonable conclusion is that injunctive norms have a different influence on descriptive norms, the latter of which had a moderate effect $(B=0.37)$ after controlling for the former.

PBC was significantly, but to a much lesser extent, mediated by intentions. This is particularly interesting because in the regression analysis, $\mathrm{PBC}$ had no significant effect on intentions but a strong, significant, positive effect on past behavior. This is only partly in line with Ajzen's [18] TPB, in which PBC is supposed to affect both intentions and behavior. Researchers have argued that individuals are unlikely to form a strong intention to do something when they lack the resources or opportunities to perform the behavior (for instance, a low PBC) [43]. In a meta-review, PBC accounted on average for 6 percent of the variance in intentions while controlling for attitudes and social norms [53]. In the literature, PBC has been significantly related to PCE [46]. In this sample, however, the overall relationships with PBC, including the one with PCE, was moderate to low. Hence, this finding could not be replicated.

In an earlier version of the ТРВ [41], the construct of personal norm was also incorporated into the model. However, personal norm was removed because the measure correlated highly with intention and the authors thought that it served as an alternative measure for behavioral intention [51]. In the present study, the correlation between moral norms and intentions was the highest among all constructs but not excessively enough to extract it from the analysis [62]. Personal norms added significantly to the explained variance in intentions when controlling for PBC, social injunctive norms, and attitudes. The study also revealed that intentions serve as a mediator between moral norms and past behavior and therefore showed no significant and positive effect on past behavior in the regression analysis. In a meta-review, including moral norms in the TPB increased the explained variance in intentions only by an average of 3 percent [53]. Since the explained variance in the present study was much higher, one can deduce that moral norms play an important role in the intention to buy local food.

In total, norms have proven to be important constructs to consider in local food buying behavior. The inference of Feldmann and Hamm [4] that local food is common across all social classes and subject to individual definitions and could therefore be less socially desirable was not true for this sample. Even though descriptive data showed the mediocre importance of norms, the regression and mediation analysis showed their significant share in explaining intentions and past behavior. Moral norms had the greatest effect on intentions among all constructs and affected past behavior through the mediator of intentions. Injunctive norms, in turn, contributed largely to explaining intentions, when not controlling for the mediator of personal norms. Descriptive norms have proven to have a different function from injunctive norms. They were only weakly moderated by personal norms and not by injunctive norms, and they mostly affected past behavior rather than intentions. In future research, structural equation modeling should be used to test whether the stated relations are indeed the way they were presented in the present thesis. Moreover, the proposed norm taxonomy by Thøgersen [19] and its underlying structure of internalization was only partly confirmed. If the results of this thesis are repeated in other studies, a revised norm theory should be developed.

Finally, the managerial implications of the results of the present thesis shall be discussed. Norm research can help marketers and decision makers in the industry understand their customers, form the basis for policies to protect the environment, and support campaigners from NGOs in persuading society of their goals [10]. As moral norms seem to play an important role in shaping the local food buying process, it will be especially interesting for decision makers to use the NAM [50]. Being aware of the potential outcomes of not buying local food (i.e., awareness of consequences) and 
feeling a sense of personal responsibility (i.e., ascription of responsibility) are the main drivers to activate norms and could be targeted in information campaigns. However, if moral norms are the core of beliefs and value systems, it will be difficult to address them directly. After all, communicating that people should feel personally obligated to buy local food does not appeal to personal but rather to external (i.e., social) norms. Nevertheless, the results showed that moral norms are internalized injunctive norms. Thus, such interventions might stimulate internalization rather than address personal norms directly. Descriptive norms have also been shown to have a considerable direct impact on behavior. Therefore, appealing to social norms may influence behavior through internalization as well as directly.

\section{Limitations and Future Research Directions}

This study has methodological limitations that can be addressed in future research. In addition to the attitude-behavior gap, there is a gap between self-reported behavior and real behavior [69]. Even though 29 percent of the self-reported past behavior could be explained, the gap between the present findings and actual behavior could be somewhat greater (or smaller). Future research could include real market data or use an experimental research design to assess the influence of norms and the other constructs used. Communicating injunctive or descriptive norms, for instance, and testing if the results differ could be another area for future studies. Since norms are difficult to measure by observation, experimental designs mixed with questionnaires would be particularly useful.

Additionally, because cross-sectional data were used in the study, no tests for causality were conducted. The empirical analyses were based on the assumptions of the models from Ajzen [18], Thøgersen [19], and Roberts [38]. Thus, if the theoretical framework of the TPB or the norm taxonomy is somehow flawed, the relations expressed could be somewhat different than stated here. Again, there is a need for experimental studies that test whether making normative beliefs salient influences actual behavior (e.g., buying local food).

Another limitation that is shared by most studies on local food is that no common understanding of local food was established. Although there is no clear definition available, in future studies, a brief statement on what local food is should be included to establish a shared understanding.

As the literature section revealed that demographics are rarely solid predictors of local food buying behavior, they were excluded from the empirical study. Other studies have found that among younger samples, norms tend to be less strongly activated because younger people are less likely to accept personal responsibility and acknowledge the consequences of their negative actions [53]. In the present study, the questionnaire was mostly sent out to students or graduates, but since demographics were not asked for, no certainty toward age can be assured. Therefore, including demographics would have helped in describing the participants and drawing conclusions. Nonetheless, assuming the younger age of the participants, norms did seem to play a major role. It would be interesting to replicate the study among an older sample to see if norms play a bigger role than in the present sample.

Furthermore, most participants were gathered from the personal network of one of the authors. As most of them were assumed to be young and well educated, this study addressed a very specific group of people. Even though the regression analysis confirmed generalizability to a wider population based on the residuals, extrapolation remains speculative. This risk was taken because participants from a higher educational background should have some knowledge of the food system and concepts of sustainability and may thus have rather activated personal norms. Without some prior awareness of sustainability, responses on issues such as product availability, PCE, and attitudes and norms toward buying local food would be highly speculative and hypothetical. As the importance of norms in local food buying behavior has been shown in the present thesis, a wider audience should be addressed in further studies. Future studies could include other sociodemographic groups or representative samples to replicate and validate the findings of this study. Further research could also test the findings in different cultures and countries. 
There are also some limitations regarding the measures used in the present study. In other studies, PBC was shown to have a relatively large effect on intentions. In the present study, PBC was not significant in the regression analysis on intentions. It is possible that if a PBC measure that better reflected the notions of local food had been used, its influence would have been bigger. Vermeir and Verbeke [45], for instance, used a measure of the perceived availability of local food to examine its impact on local food buying behavior. Items that reflect difficulties in identifying local food could also be included in the constructs of future studies.

Author Contributions: Julius Wenzig and Tim Gruchmann both hold an academic position at the Centre for Sustainable Leadership at Witten/Herdecke University. In addition, Tim Gruchmann is PhD candidate at the University of Kassel. The present study is based on the master thesis by Julius Wenzig. The authors designed the study jointly. Julius Wenzig conducted the data collection and analysis and contributed mainly to the writing of all sections of the paper. Tim Gruchmann also contributed to the writing of all sections and was the main contributors to the revision of the paper.

Acknowledgments: The authors would like to thank the reviewers and editors for their valuable and constructive comments, which have led to a significant improvement of the manuscript. Moreover, we would like to express our sincere gratitude to Prof. Dr. Andrea Calabrò and Dr. Giovanna Campopiano from Witten/Herdecke University for their guidance and help within the whole research process.

Conflicts of Interest: The author declares no conflict of interest.

\section{References}

1. Vermeir, I.; Verbeke, W. Sustainable food consumption: Exploring the consumer "attitude-behavioral intention" gap. J. Agric. Environ. Eth. 2006, 19, 169-194. [CrossRef]

2. Melkonyan, A.; Krumme, K.; Gruchmann, T.; De La Torre, G. Sustainability assessment and climate change resilience in food production and supply. Ener. Proc. 2017, 123, 131-138. [CrossRef]

3. Khan, F.; Prior, C. Evaluating the urban consumer with regard to sourcing local food: A heart of England study. Int. J. Consum. Stud. 2010, 34, 161-168. [CrossRef]

4. Feldmann, C.; Hamm, U. Consumers' perceptions and preferences for local food: A review. Food Qual. Prefer. 2015, 40, 152-164. [CrossRef]

5. Sirieix, L.; Delanchy, M.; Remaud, H.; Zepeda, L.; Gurviez, P. Consumers' perceptions of individual and combined sustainable food labels: A UK pilot investigation. Int. J. Consum. Stud. 2013, 37, $143-151$. [CrossRef]

6. Lorenz, B.A.; Hartmann, M.; Simons, J. Impacts from region-of-origin labeling on consumer product perception and purchasing intention—causal relationships in a TPB based model. Food Qual. Prefer. 2015, 45, 149-157. [CrossRef]

7. Parker, D.; Manstead, A.S.R.; Stradling, S.G. Extending the theory of planned behaviour: The role of personal norm. Br. J. Soc. Psychol. 1995, 34, 127-138. [CrossRef]

8. Cialdini, R.B.; Reno, R.R.; Kallgren, C.A. A focus theory of normative conduct: Recycling the concept of norms to reduce littering in public places. J. Person. Soc. Psychol. 1990, 58, 1015-1026. [CrossRef]

9. Thøgersen, J. Social norms and cooperation in real-life social dilemmas. J. Econ. Psychol. 2008, $29,458-472$. [CrossRef]

10. Thøgersen, J. The motivational roots of norms for environmentally responsible behavior. Basic Appl. Soc. Psychol. 2009, 31, 348-362. [CrossRef]

11. Armitage, C.J.; Conner, M. Efficacy of the theory of planned behaviour: A meta analytic review. Br. J. Soc. Psychol. 2001, 40, 471-499. [CrossRef] [PubMed]

12. Doran, R.; Larsen, S. The relative importance of social and personal norms in explaining intentions to choose eco-friendly travel options. Int. J. Tour. Res. 2016, 18, 159-166. [CrossRef]

13. Klöckner, C.A.; Nayum, A.; Mehmetoglu, M. Positive and negative spillover effects from electric car purchase to car use. Transp. Res. Part D 2013, 21, 32-38. [CrossRef]

14. Guagnano, G.A.; Stern, P.C.; Dietz, T. Influences on attitude-behavior relationships. Environ. Behav. 1995, 27, 699-718. [CrossRef]

15. Thøgersen, J. Recycling and morality: A critical review of the literature. Environ. Behav. 1996, 28, 536-558. [CrossRef] 
16. Dean, M.; Raats, M.M.; Shepherd, R. Moral concerns and consumer choice of fresh and processed organic foods. J. Appl. Soc. Psychol. 2008, 38, 2088-2107. [CrossRef]

17. Kumar, A.; Smith, S. Understanding local food consumers: Theory of planned behavior and segmentation approach. J. Food Prod. Mark. 2018, 24, 196-215. [CrossRef]

18. Ajzen, I. The theory of planned behavior. Organ. Behav. Hum. Decis. Process. 1991, 50, 179-211. [CrossRef]

19. Thøgersen, J. Norms for environmentally responsible behaviour: An extended taxonomy. J. Environ. Psychol. 2006, 26, 247-261. [CrossRef]

20. Onozaka, Y.; Nurse, G.; McFadde, D.T. Local food consumers: How motivations and perceptions translate to buying behavior. Choices 2010, 25, 1-6.

21. Cranfield, J.; Henson, S.; Blandon, J. The effect of attitudinal and sociodemographic factors on the likelihood of buying locally produced food. Agribusiness 2012, 205-221. [CrossRef]

22. Zepeda, L.; Leviten-Reid, C. Consumers' views on local food. J. Food Distrib. Res. 2004, 35, 1-6.

23. Adams, D.C.; Adams, A.E. De-placing local at the farmers' market: Consumer conceptions of local food. J. Rural Soc. Sci. 2011, 26, 74-100.

24. Stockebrand, N.; Spiller, A. Regionale Lebensmittel: Sprechen Kunden und Unternehmen die gleiche Sprache? In Werte—Wege-Wirkungen: Biolandbau im Spannungsfeld zwischen Ernährungssicherung, Markt und Klimawandel: Band 2: Tierhaltung, Agrarpolitik und Betriebswirtschaft, Märkte und Lebensmittel; Mayer, J., Alföldi, T., Leiber, F., Dubois, D., Fried, P., Heckendorn, F., Hillmann, E., Klocke, P., Lüscher, A., Riedel, S., Eds.; Verlag Dr. Köster: Berlin, Germany, 2009; pp. 342-345.

25. Zepeda, L.; Deal, D. Organic and local food consumer behaviour: Alphabet theory. Int. J. Consum. Stud. 2009, 33, 697-705. [CrossRef]

26. Tregear, A.; Ness, M. Discriminant analysis of consumer interest in buying locally produced foods. J. Mark. Manag. 2005, 21, 19-35. [CrossRef]

27. Yue, C.; Tong, C. Organic or local? Investigating consumer preference for fresh produce using a choice experiment with real economic incentives. Hort Sci. 2009, 44, 366-371.

28. Bond, J.K.; Thilmany, D.; Bond, C. What influences consumer choice of fresh produce purchase location? J. Agric. Appl. Econ. 2009, 41,61-74. [CrossRef]

29. Zepeda, L.; Li, J. Who buys local food? J. Food Distrib. Res. 2006, 37, 5-15.

30. Conner, D.; Colasanti, K.; Ross, R.B.; Smalley, S.B. Locally grown foods and farmers markets: Consumer attitudes and behaviors. Sustainability 2010, 2, 742-756. [CrossRef]

31. Megicks, P.; Memery, J.; Angell, R.J. Understanding local food shopping: Unpacking the ethical dimension. J. Mark. Manag. 2012, 28, 264-289. [CrossRef]

32. Zepeda, L.; Nie, C. What are the odds of being an organic or local food shopper? Multivariate analysis of US food shopper lifestyle segments. Agric. Hum. Values 2012, 29, 467-480. [CrossRef]

33. Chambers, S.; Lobb, A.; Butler, L.; Harvey, K.; Traill, W.B. Local, national and imported foods: A qualitative study. Appetite 2007, 49, 208-213. [CrossRef] [PubMed]

34. Born, B.; Purcell, M. Avoiding the local trap: Scale and food systems in planning research. J. Plan. Educ. Res. 2006, 26, 195-207. [CrossRef]

35. Darby, K.; Batte, M.T.; Ernst, S.; Roe, B. Decomposing local: A conjoint analysis of locally produced foods. Am. J. Agric. Econ. 2008, 90, 476-486. [CrossRef]

36. Kolodinsky, J.M.; Pelch, L.L. Factors influencing the decision to join a community supported agriculture (CSA) farm. J. Sustain. Agric. 1997, 10, 129-141. [CrossRef]

37. Weatherell, C.; Tregear, A.; Allinson, J. In search of the concerned consumer: UK public perceptions of food, farming and buying local. J. Rural Stud. 2003, 19, 233-244. [CrossRef]

38. Roberts, J.A. Green consumers in the 1990s: Profile and implications for advertising. J. Bus. Res. 1996, 36, 217-231. [CrossRef]

39. Ajzen, I. From intentions to actions: A theory of planned behavior. In Action Control: From Cognition to Behavior; Kuhl, J., Beckmann, J., Eds.; Springer: Berlin, Germany, 1985; pp. 11-39.

40. Ajzen, I.; Fishbein, M. Understanding attitudes and predicting social behavior. In Englewood Cliffs; Prentice-Hall: New York, NY, USA, 1980.

41. Fishbein, M.; Ajzen, I. Belief, Attitude, Intention and Behavior: An Introduction to Theory and Research; Addison-Wesley Series in Social Psychology; Addison-Wesley: Reading, MA, USA, 1975. 
42. Teng, C.-C.; Wang, Y.-M. Decisional factors driving organic food consumption. Br. Food J. 2015, 117, $1066-1081$. [CrossRef]

43. Shah Alam, S.; Mohamed Sayuti, N. Applying the theory of planned behavior (TPB) in halal food purchasing. Int. J. Commer. Manag. 2011, 21, 8-20. [CrossRef]

44. Ajzen, I. Perceived behavioral control, self-efficacy, locus of control, and the theory of planned behavior. J. Appl. Soc. Psychol. 2002, 32, 665-683. [CrossRef]

45. Vermeir, I.; Verbeke, W. Sustainable food consumption among young adults in Belgium: Theory of planned behaviour and the role of confidence and values. Ecol. Econ. 2008, 64, 542-553. [CrossRef]

46. Sparks, P.; Guthrie, C.A.; Shepherd, R. The dimensional structure of the perceived behavioral control construct. J. Appl. Soc. Psychol. 1997, 27, 418-438. [CrossRef]

47. Sparks, P.; Shepherd, R. Self-identity and the theory of planned behavior: Assessing the role of identification with "green consumerism". Soc. Psychol. Q. 1992, 55, 388. [CrossRef]

48. Aertsens, J.; Verbeke, W.; Mondelaers, K.; van Huylenbroeck, G. Personal determinants of organic food consumption: A review. Br. Food J. 2009, 111, 1140-1167. [CrossRef]

49. Nurse Rainbolt, G.; Onozaka, Y.; McFadden, D.T. Consumer motivations and buying behavior: The case of the local food system movement. J. Food Prod. Mark. 2012, 18, 385-396. [CrossRef]

50. Schwartz, S.H. Normative influences on altruism. In Advances in Experimental Social Psychology; Berkowitz, L., Ed.; Academic Press: New York, NY, USA, 1977; pp. 221-279.

51. Harland, P.; Staats, H.; Wilke, H.A.M. Explaining proenvironmental intention and behavior by personal norms and the theory of planned behavior. J. Appl. Soc. Psychol. 1999, 29, 2505-2528. [CrossRef]

52. Onwezen, M.C.; Antonides, G.; Bartels, J. The norm activation model: An exploration of the functions of anticipated pride and guilt in pro-environmental behaviour. J. Econ. Psychol. 2013, 39, 141-153. [CrossRef]

53. Rivis, A.; Sheeran, P.; Armitage, C.J. Expanding the affective and normative components of the theory of planned behavior: A meta-analysis of anticipated affect and moral norms. J. Appl. Soc. Psychol. 2009, 39, 2985-3019. [CrossRef]

54. Deci, E.L.; Ryan, R.M. Conceptualizations of intrinsic motivation and self-determination. In Intrinsic Motivation and Self-Determination in Human Behavior; Deci, E.L., Ryan, R.M., Eds.; Springer: Boston, MA, USA, 1985; pp. 11-40.

55. Ryan, R.M.; Deci, E.L. Self-determination theory and the facilitation of intrinsic motivation, social development, and well-being. Am. Psychol. 2000, 55, 68-78. [CrossRef] [PubMed]

56. Kohlberg, L. The Psychology of Moral Development: The Nature and Validity of Moral Stages; Essays on Moral Development; Harper \& Row: Cambridge, UK, 1984.

57. Povey, R.; Conner, M.; Sparks, P.; James, R.; Shepherd, R. The theory of planned behaviour and healthy eating: Examining additive and moderating effects of social influence variables. Psychol. Health 2000, 14, 991-1006. [CrossRef] [PubMed]

58. Preston, C.C.; Colman, A.M. Optimal number of response categories in rating scales: Reliability, validity, discriminating power, and respondent preferences. Acta Psychol. 2000, 104, 1-15. [CrossRef]

59. Peterson, R.A. A Meta-Analysis of Cronbach's Coefficient Alpha. J. Consum. Res. 1994, 21, 381. [CrossRef]

60. Armitage, C.J. Can the theory of planned behavior predict the maintenance of physical activity? Health Psychol. Off. J. Div. Health Psychol. Am. Psychol. Assoc. 2005, 24, 235-245. [CrossRef] [PubMed]

61. Sparks, P.; Conner, M.; James, R.; Shepherd, R.; Povey, R. Ambivalence about health related behaviours: An exploration in the domain of food choice. Br. J. Health Psychol. 2001, 6, 53-68. [CrossRef] [PubMed]

62. Field, A. Discovering Statistics Using SPSS; Sage: Los Angeles, CA, USA, 2009.

63. DiStefano, C.; Zhu, M.; Mindrila, D. Understanding and using factor scores: Considerations for the applied researcher. Pract. Assess. Res. Eval. 2009, 14, 1-11.

64. Hayes, A.F. Introduction to Mediation, Moderation, and Conditional Process Analysis: A Regression-Based Approach. Methodology in the Social Sciences; Guilford Press: New York, NY, USA, 2013.

65. Hayes, A.F.; Rockwood, N.J. Regression-based statistical mediation and moderation analysis in clinical research: Observations, recommendations, and implementation. Behav. Res. Ther. 2017, 98, 39-57. [CrossRef] [PubMed]

66. Baron, R.M.; Kenny, D.A. The moderator-mediator variable distinction in social psychological research: Conceptual, strategic, and statistical considerations. J. Person. Soc. Psychol. 1986, 51, 1173-1182. [CrossRef] 
67. Wen, Z.; Fan, X. Monotonicity of effect sizes: Questioning kappa-squared as mediation effect size measure. Psychol. Methods 2015, 20, 193-203. [CrossRef] [PubMed]

68. Miočević, M.; O’Rourke, H.P.; MacKinnon, D.P.; Brown, H.C. Statistical properties of four effect-size measures for mediation models. Behav. Res. Methods 2018, 50, 285-301. [CrossRef] [PubMed]

69. Bamberg, S.; Möser, G. Twenty years after Hines, Hungerford, and Tomera: A new meta-analysis of psycho-social determinants of pro-environmental behaviour. J. Environ. Psychol. 2007, 27, 14-25. [CrossRef]

70. Smith, J.R.; Louis, W.R.; Terry, D.J.; Greenaway, K.H.; Clarke, M.R.; Cheng, X. Congruent or conflicted?: The impact of injunctive and descriptive norms on environmental intentions. J. Environ. Psychol. 2012, 32, 353-361. [CrossRef]

71. Jackson, C.; Smith, R.A.; Conner, M. Applying an extended version of the theory of planned behaviour to physical activity. J. Sports Sci. 2003, 21, 119-133. [CrossRef] [PubMed]

(c) 2018 by the authors. Licensee MDPI, Basel, Switzerland. This article is an open access article distributed under the terms and conditions of the Creative Commons Attribution (CC BY) license (http://creativecommons.org/licenses/by/4.0/). 